Research Article

\title{
Examination of the Magnetic Properties in the Magnetic Circuits Formed by a Printing Technique
}

\author{
Adam Jakubas (ii) \\ Faculty of Electrical Engineering, Czestochowa University of Technology, 42-200 Czestochowa, Poland \\ Correspondence should be addressed to Adam Jakubas; adam.jakubas@gmail.com
}

Received 21 November 2018; Accepted 7 April 2019; Published 2 May 2019

Academic Editor: Hiroshi Yoshihara

Copyright (c) 2019 Adam Jakubas. This is an open access article distributed under the Creative Commons Attribution License, which permits unrestricted use, distribution, and reproduction in any medium, provided the original work is properly cited.

In mass printing of specialist coatings on cellulose substrates, their thickness is an important factor influencing the usefulness of such coatings. The paper presented the results of testing the magnetic properties of a printing paint admixture with iron powder with a grain size $<10 \mu \mathrm{m}$. Experimental studies were carried out on samples with three magnetic coating thicknesses: $0.2,0.25$, and 0.3 , respectively. The obtained induction and magnetic field values were used to determine the relationship between the thickness of magnetic paint and its magnetic permeability. The obtained maximum values of $\mu_{\mathrm{r}}$ were 10,11.5, and 12.5 for samples with a thickness of $0.2,0.25$, and $0.3 \mathrm{~mm}$, respectively. The value of magnetic permeability increased with the increase of coating thickness. The analysis of the properties of coatings has been supplemented with the mathematical description of the relationship between material parameters and hysteresis in magnetic materials. The proposed elliptical hysteresis approximation significantly facilitates a design and prediction of the properties of finished products. The analysis of the equivalent hysteresis angle $\delta$ showed almost linear dependence on the coating thickness. The proposed indicator (angle $\delta$ ) allows a quick and simple way to verify the thickness of magnetic coatings on flexible diamagnetic substrates in production conditions.

\section{Introduction}

Printed electronics enables one to carry out the economical mass production of elements with low- and mediumcomplex structures, using traditional printing methods: screen printing, offset printing, stream printing, and others. Traditional methods of printing produce conductive, dielectric, luminescent, or sensitive layers for various physical or chemical influences. Examples of a technology containing printed elements are electrical circuits $[1,2]$, flexible power sources [3], and RFID antennas. Printed electronics allow making electronic components on very diverse substrates, both rigid and flexible [4]. The technology of printed electronics can also be used for paper substrates, glasses, or even textiles (textronics) [5].

The printing uses, among others, hard and soft magnetic paints. Their use allows reading, storing, and updating various types of information for automatic reading on various documents [6]. The information carriers in such documents are microprocessors and magnetic paints. The recording and reading of data are possible due to the ferromagnetic properties of paint (the organization of Weiss domains in its structure due to the action of magnetic field). The magnetized paints have very high technological requirements. In addition to the typical properties of the printing process, they must maintain the appropriate magnetic characteristics, i.e., magnetic coercivity, remanent magnetization, saturation, magnetization, magnetic induction, magnetic losses, and magnetic field strength. Components which allow one for magnetization are magnetic pigments, among others iron oxide or barium ferrite. The use of these pigments significantly limits the range of the colour palette and causes the absorption of IR rays. Usually, the paint check is carried out in laboratory conditions using vibration magnetometers (VSMs), and the result is presented in the form of hysteresis loop [7]. This is particularly difficult in the case of prints with a thickness of tens of $\mu \mathrm{m}$ applied to diamagnetic substrates of similar thickness and the use of nondestructive methods. Due to 
low induction values (usually $<0.1 \mathrm{~T}$ ), high surface resistance $(M \Omega)$, and type of substrate (paper, polymer, and textiles), it is impossible or very difficult to use ultrasonic, magnetic, electromagnetic, or eddy current gauges $[8,9]$. As a result, an effective measurement of the thickness of the magnetic paint applied to nonmagnetic substrates can be made using photothermal measuring devices like Paintchecker mobile infrared $[10,11]$ or an analogue thickness gauge. The paper presents an alternative method of nondestructive thickness measurement of such coatings using magnetic permeability analysis and the elliptical hysteresis approximation.

\section{Materials and Methods}

Several samples of magnetic mixtures have been prepared from paint PANTONE ${ }^{\circledR}$ Transparent White and iron powder (spherical shape, $<10 \mu \mathrm{m}, 99.9+\%$ purity, Alfa Aesar). Fine structure of both components allowed us to obtain highly homogeneous mixtures. The choice of iron powder is the result of previous research on soft magnetic composites (SMCs). In the works [12-15], it was found that there is a relationship between the size of grains and the level of magnetic induction (generally, larger grains allow us to achieve a higher $B$ at the same level of $H$ ). The weight proportions of the components have been selected so that the magnetic paint is suitable for offset printing. Samples (Figure 1) in the form of strips $20 \mathrm{~cm}$ long and $4 \mathrm{~cm}$ wide were made using a laboratory printing machine (Figure 2).

The device is designed for making test prints from offset inks. The paint is distributed using 3 rollers; two of the metals ( $a$ and $b$ ) exhibit the reciprocating movement that guarantees an even distribution, and one is coated with rubber (c). After uniform distribution on all rollers, the printing roller (d) mounted on the movable lever (e) is adjusted. When the printing roll is covered with paint, it is transferred to the printing part of the device and the printing material is placed on the lever. The printout occurs after pressing (f) with the appropriate roll force and activating the button $(\mathrm{g})$ setting the roller in motion.

In order to obtain the desired coating thickness, the paint was applied many times (after drying of the previous layer) on $80 \mathrm{~g} / \mathrm{m}^{2}$ paper (a similar one is used for public transport tickets). Finally, samples with magnetic coating thicknesses of $0.2,0.25$, and $0.3 \mathrm{~mm}$ were obtained. The samples were then adapted to the requirements of the measuring system. The samples were cut to dimensions of $15 \times 3 \mathrm{~cm}$.

In order to determine the magnetic properties, the Remacomp C-200 computer measuring system was used (see Figure 3). The international standard IEC 60404-2 [16] recommends the wattmeter method with the Epstein test frame or toroidal sample as the basic measurement method of specific magnetic losses $P$. These properties can also be measured using other methods, such as the hysteresis graph or calorimetric methods or the unbalanced bridge method [17].

The system is based on the wattmeter method. The magnetic field strength $H$ is determined directly from the voltage drop of the magnetizing current across the

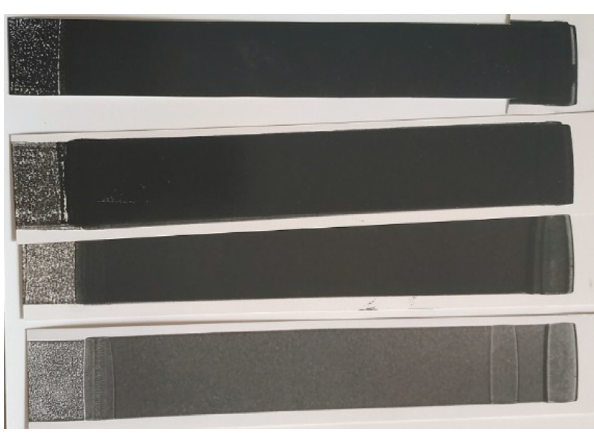

FIgURE 1: Examples of printing strips.

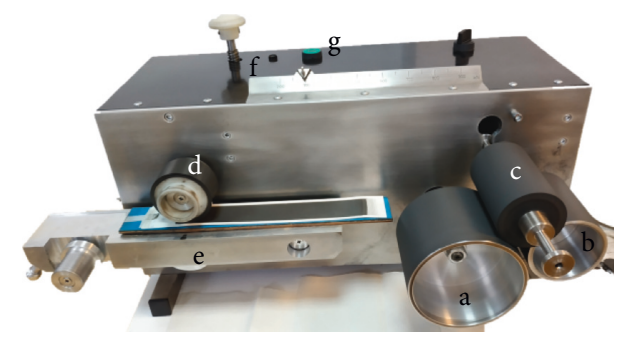

FIGURE 2: Laboratory paint tester.

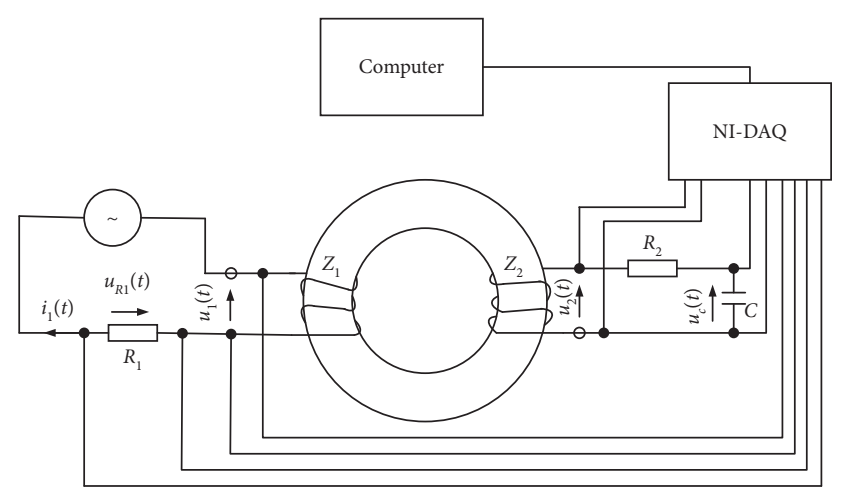

Figure 3: Scheme of connection for the measurement setup.

measuring shunt resistor $R$. The resulting voltage and the voltage induced in the secondary winding are simultaneously sampled by two fast analogue-to-digital converters. Voltage induced in the secondary winding is numerically integrated to calculate the magnetic induction $B$ and the polarization $J$. The time functions of $H$ and $B$ are used for further evaluation in order to display the hysteresis loop, the loss or permeability curves, etc. [18].

The samples placed in the MJC measuring yokes (see Figure 4) were measured at $20 \mathrm{~Hz}, 50 \mathrm{~Hz}, 100 \mathrm{~Hz}, 500 \mathrm{~Hz}$, and $1000 \mathrm{~Hz}$ at the maximum magnetic field varying from $1 \mathrm{kA} / \mathrm{m}$ to $15 \mathrm{kA} / \mathrm{m}$. The measurements were carried out according to the standards, i.e., for the sine waveform of magnetic induction inside the sample. The measuring yokes contain integrated field generating and measuring coils. They are designed to measure magnetic strips and sheet. The yokes are laminated and made from low core loss material.

The mathematical description of the relationship between material parameters and hysteresis in magnetic 


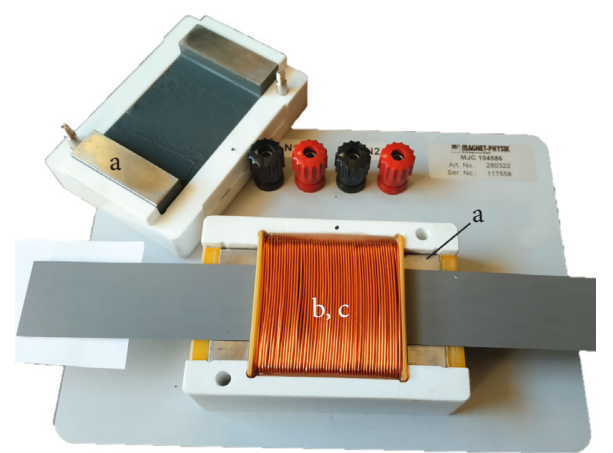

(a)

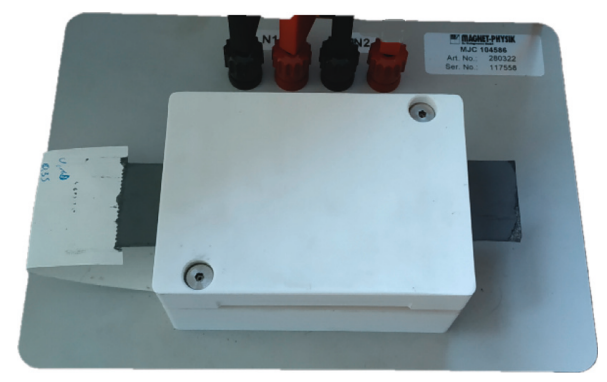

(b)

Figure 4: Connection for the measurement setup without cover and with cover where a represents yokes and $b$ and $c$ denote primary and secondary windings.

materials significantly facilitates the design and prediction of the properties of finished products. Among various descriptions of hysteresis in the magnetic composites, the following models attracted the attention of researchers and engineers: the phenomenological model $T(x)[19,20]$, Jiles-Atherton's approach [21] and its modifications $[22,23]$, the Preisach $[24,25]$ model, and GRUCAD [26] model. However, for the considered composite, the author focused on yet another possible method of handling the problem, namely, the introduction of elliptical hysteresis approximation into calculations. The reason is the need to develop a simple engineering tool for determining layer thickness without having to go into the physical aspects of the problem. In addition, the elliptical model accurately reflects the loop shape of this type of material, which has very narrow hysteresis loops in respect of the field of strength value. The idea was proposed almost five decades ago by Professor Zakrzewski [27] and subsequently examined in a number of papers [28-31]. The replacement of actual, most often sigmoid-like, shape of hysteresis loop with an ellipse allows one to simplify the calculations of electromagnetic field distribution at little sacrifice of accuracy, acceptable for engineering purposes. Originally, the elliptic model is used to determine power losses in ferromagnetic materials (equation (1)). In the case under consideration, it was used to determine the parameters that allow one for calculating the thickness of the magnetic paint layer.

In Ref. [27], the following formula for calculation of loss density, $W / \mathrm{kg}$, has been introduced:

$$
P=\frac{k^{3}}{2 \sigma \mu_{m}^{2} \gamma d} \phi_{m}^{2} \xi_{\phi},
$$

where $H_{m}$ denotes the amplitude of magnetic field strength forced on the surface of lamination $(\mathrm{A} / \mathrm{m}), \gamma$ is the material density $\left(\mathrm{kg} / \mathrm{m}^{3}\right)$, and $d$ is the lamination thickness $(\mathrm{m})$, whereas $\xi_{\phi}$ is given with the expression

$$
\xi_{\phi}=\frac{a \sinh (a k d)-b \sin (b k d)}{\cosh (a k d)+\cos (b k d)},
$$

where $a$ and $b$ are the correction coefficients related to the equivalent hysteresis (lag) angle $d$ :

$$
\begin{aligned}
& a=\cos \frac{\delta}{2}+\sin \frac{\delta}{2}, \\
& b=\cos \frac{\delta}{2}+\sin \frac{\delta}{2} .
\end{aligned}
$$

The equivalent hysteresis (lag) angle $\delta$ is defined on the basis of measurement data with equation (1)

$$
\delta=\arcsin \frac{A^{*}}{\pi B_{m}^{*} H_{m}^{*}},
$$

where $A^{*}$ is the area of hysteresis loop, $B_{m}^{*}$ and $H_{m}^{*}$ are the magnetic induction, $T$, and magnetic field strength, $\mathrm{A} / \mathrm{m}$, respectively.

The coefficient $k, 1 / \mathrm{m}$, describing attenuation of electromagnetic wave in the material is given as

$$
k=\sqrt{\pi f \mu_{m} \sigma},
$$

where $\sigma$ denotes conductivity, $\mathrm{S} / \mathrm{m}$.

Flux $\phi_{m}$ in relationship (1) is related to the average induction in the material and it is expressed in unusual units $T_{m}=V \mathrm{~S} / \mathrm{m}$ (it is given per $1 \mathrm{~m}$ of layer width).

This approach introduced equivalent permeability (by replacing the true shape of hysteresis loop with an ellipse) and made it possible to simplify calculations of spatial distribution of electromagnetic quantities within the ferromagnetic sample.

\section{Results and Discussion}

The dependencies of magnetization curve shapes on coating (paint) thickness for the composite structure (substrate + coating) are shown in Figure 5. As the hysteresis shapes for the examined samples resemble to much extent ellipses, it is natural to use the elliptical loop approximation for their description.

The results have a clear relationship with the relative permeability of the whole sample (paper + paint) shown in Figure 6. The obtained maximum values of $\mu_{\mathrm{r}}$ are $10,11.5$, and 12.5 , respectively, for samples with a thickness of 0.2 , 0.25 , and $0.3 \mathrm{~mm}$. 


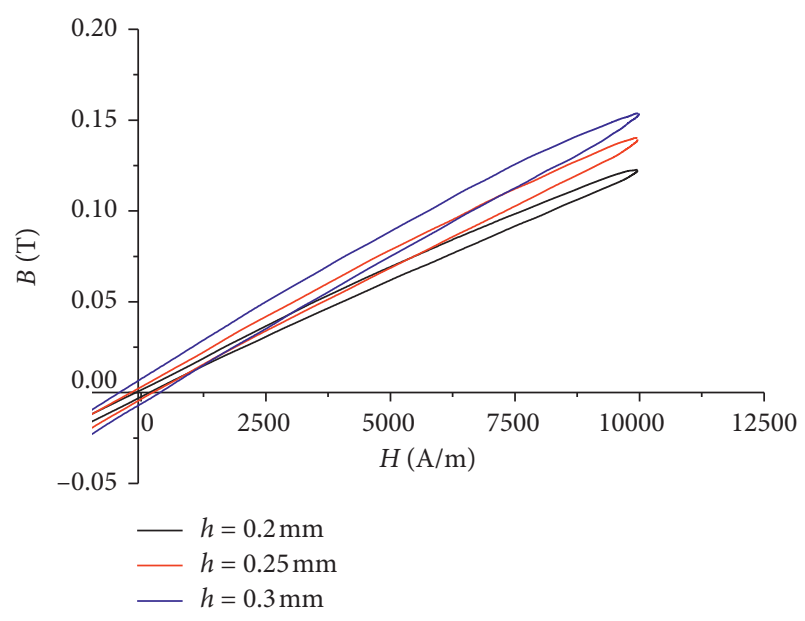

FIGURE 5: Loops shape for different thicknesses of paint layer.

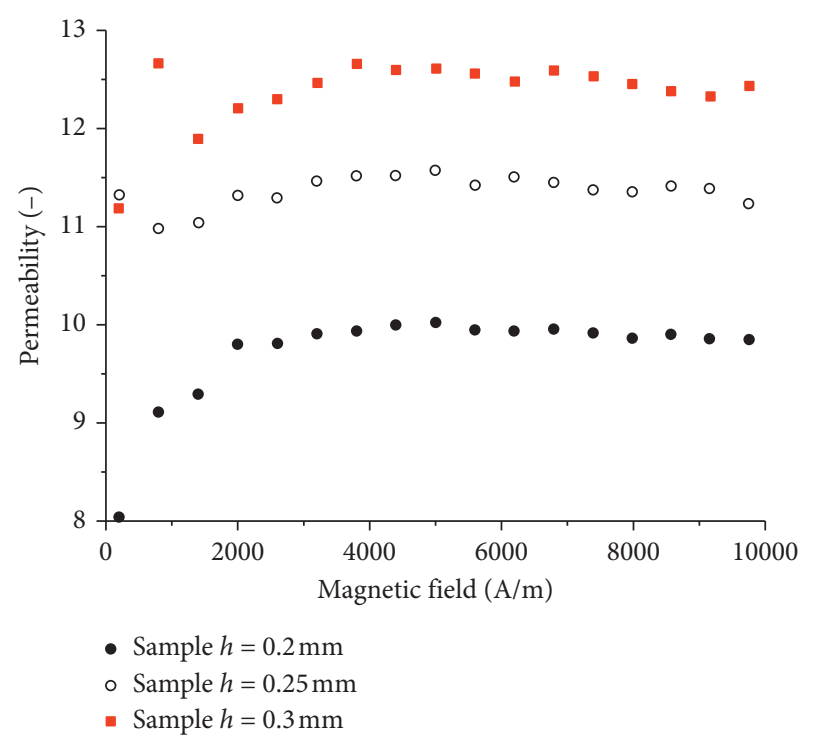

Figure 6: Magnetic permeability values for samples with different thicknesses.

In order to find an explicit formula or the angle versus coating layer thickness, the $B(H)$ dependence has been recast into $M(H)$ dependence using the constitutive relationship:

$$
B=\mu_{0}(H+M) \text {. }
$$

The reason for this step is that magnetization (which is a quantity that is not directly measurable) and field strength have then the same units, $\mathrm{A} / \mathrm{m}$. The hysteresis angles for different thicknesses have been computed using a freeware Matlab script available from Mathworks File Exchange [32].

This function uses the least squares criterion for estimation of the best fit to an ellipse from a given set of points $(x, y)$. The LS estimation is done for the conic representation of the ellipse with a possible tilt. Conic ellipse representation is as follows:

$$
a x^{2}+b x y+c y^{2}+d x e y+f=0,
$$

where $x$ and $y$ are the coordinates of a point from a single measurement and $a, b, c, d$, and $e$ are model parameters. Tilt/

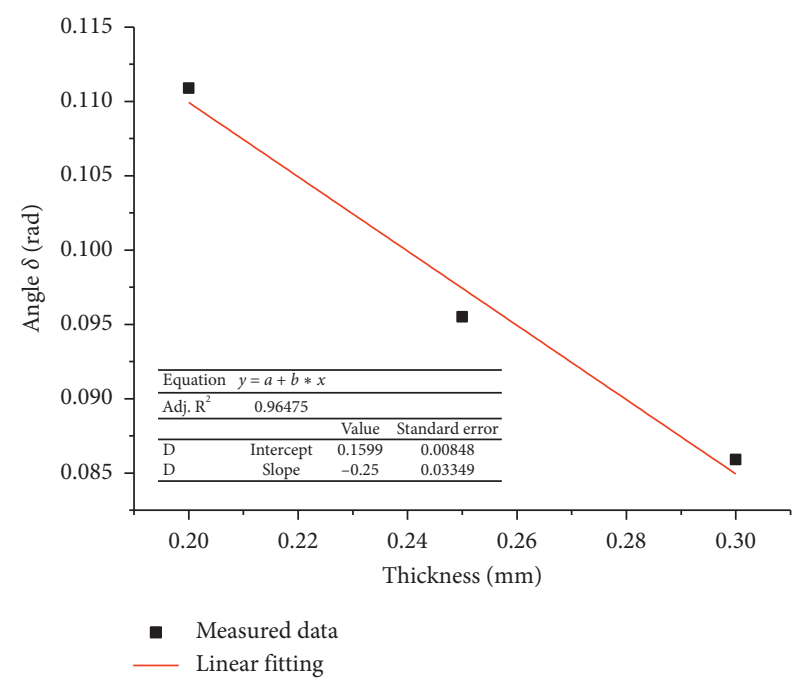

FIGURE 7: Dependence of the angle $\delta$ on the thickness of the layer.

orientation for the ellipse occurs when the term $x \times y$ exists (i.e., $b \approx 0$ ). After the estimation, the tilt is removed from the ellipse (using a rotation matrix) and then, the rest of the parameters which describe an ellipse are extracted from the conic representation. The script returns the values of 5 parameters of the ellipse (coefficients $a, b, c, d$, and $e$ ).

Figure 7 shows the dependence of the angle $\delta$ on the thickness of the magnetic layer.

\section{Conclusions}

These studies have enabled the development of a method for measuring the thickness of a coating made of magnetic paint useful in production conditions. Based on the analysis of the obtained measurement results, it can be stated that the value of magnetic permeability or equivalent hysteresis angle $\delta$ of magnetic paint applied to a paper substrate can be an effective method in determining the thickness. In the case at hand, the thickness of both layers (paint + paper) was of the same order of magnitude and this is typical for this type of real products.

(i) Samples made of the same printing ink composition were analysed.

(ii) Commercially available semi-finished products were used.

(iii) Different thicknesses of the coating (0.2, 0.25, $0.30 \mathrm{~mm}$ ) were obtained by applying successive layers of paint.

(iv) A measurement procedure designed to measure magnetic strips and sheet was used.

(v) Values of angle $\delta$ were obtained, respectively: $h=0.2-0.1109 ; h=0.25-0.0955 ; h=0.3-0.0859 \mathrm{rad}$.

(vi) The results are convergent with the trends in permeability measurements $\left(\mu_{\mathrm{r}}\right.$ is $10,11.5$, and 12.5 , respectively) and magnetic induction (respectively, $B(\mathrm{~T})$ is $0.1223,0.140$, and 0.153 ). However, they give more readable information in direct correlation to the thickness of the coating. 
(vii) The analysis of the equivalent hysteresis angle $\delta$ showed almost linear dependence on the coating thickness.

The proposed indicator (angle $\delta$ ) allows one for a quick and simple way to verify the thickness of magnetic coatings on flexible diamagnetic substrates in production conditions. Thus, it can be used in rough measurements for determination of magnetic layer thickness.

\section{Data Availability}

The measured hysteresis loop data used to support the findings of this study are available from the corresponding author upon request. The script "fit_ellipse.m" used to support the findings of this study was supplied by Ohad Gal under free access license and is available from Mathworks File Exchange.

\section{Conflicts of Interest}

The author declares that there are no conflicts of interest regarding the publication of this paper.

\section{Acknowledgments}

This work was supported by the Regional Operational Program of the Silesia Province (Project no. WNDRPSL.01.02.00-24-06G9/16-004).

\section{References}

[1] E. Korzeniewska, M. Walczak, and J. Rymaszewski, "Elements of elastic electronics created on textile substrate," in Proceedings of the MIXDES-24th International Conference Mixed Design of Integrated Circuits and Systems, pp. 447-450, IEEE, Bydgoszcz, Poland, June 2017.

[2] M. M. Hamedi, A. Ainla, F. Güder, D. C. Christodouleas, M. T. Fernández-Abedul, and G. M. Whitesides, "Integrating electronics and microfluidics on paper," Advanced Materials, vol. 28, no. 25, pp. 5054-5063, 2016.

[3] K.-H. Choi, J. Yoo, C. K. Lee, and S.-Y. Lee, "All-inkjetprinted, solid-state flexible supercapacitors on paper," Energy \& Environmental Science, vol. 9, no. 9, pp. 2812-2821, 2016.

[4] M. Tayyab, M. S. Sharawi, A. Shamim, and A. Al-Sarkhi, "A low complexity RF based sensor array for lung disease detection using inkjet printing," International Journal of RF and Microwave Computer-Aided Engineering, vol. 29, no. 4, article e21586, 2019.

[5] Z. Stempien, E. Rybicki, T. Rybicki, and J. Lesnikowski, "Inkjet-printing deposition of silver electro-conductive layers on textile substrates at low sintering temperature by using an aqueous silver ions-containing ink for textronic applications," Sensors and Actuators B: Chemical, vol. 224, pp. 714-725, 2016.

[6] D. A. Thompson and J. S. Best, "The future of magnetic data storage techology," IBM Journal of Research and Development, vol. 44, no. 3, pp. 311-322, 2000.

[7] R. Nowosielski, M. Kądziołka-Gaweł, P. Gębara, D. Szyba, and R. Babilas, "Magnetic properties and structure after crystallization of $\mathrm{Fe}_{80-x} \mathrm{~B}_{20} \mathrm{Nb}_{x}(x=4,6,10)$ metallic glasses," Acta Physica Polonica A, vol. 131, no. 5, pp. 1212-1217, 2017.
[8] R. Janiczek and P. Ptak, "Przetworniki indukcyjnościowe w pomiarach grubości warstw wierzchnich," Przegląd Elektrotechniczny, vol. 83, pp. 86-90, 2007.

[9] L. Borowik and A. Jakubas, "Modeling of four-electrode system to determine the resistance of antistatic coatingsoptimization of the dimensions of the electrode system," Journal of Electrostatics, vol. 75, pp. 54-62, 2015.

[10] E. Welsch and D. Ristau, "Photothermal measurements on optical thin films," Applied Optics, vol. 34, no. 31, pp. 72397253, 1995.

[11] Information about device Paintchecker Mobile Infrared, http://www.optisense.com.

[12] A. Jakubas, P. Gębara, S. Seme, A. Gnatowski, and K. Chwastek, "Magnetic properties of SMC cores produced at a low compacting temperature," Acta Physica Polonica A, vol. 131, no. 5, pp. 1289-1294, 2017.

[13] A. Jakubas, "Modeling of the effect of grain size on hysteresis curves using the takács model," in Proceedings of the 2018 Progress in Applied Electrical Engineering (PAEE), p. 4, IEEE, Koscielisko, Poland, June 2018.

[14] R. Jastrzębski, A. Jakubas, and K. Chwastek, "Relationships between grain size in self-developed soft magnetic composites and the Grucad hysteresis model," Journal of Electrical Engineering-Elektrotechnicky Casopis, vol. 69, no. 6, pp. 485-488, 2018.

[15] A. Jakubas and M. Najgebauer, "Influence of manufacturing parameters on magnetic parameters of soft magnetic composites cores," Journal of Electrical Engineering, vol. 69, no. 6, pp. 442-444, 2018.

[16] IEC 60404-2, Magnetic Materials-Part 2: Methods of Measurement of the Magnetic Properties of Electrical Steel Strip and Sheet by Means of an Epstein Frame, International Electrotechnical Commission (IEC), Geneva, Switzerland, 2008.

[17] A. Majocha and R. Gozdur, "Bridge method of measurements of the power loss," Przeglad Elektrotechniczny, vol. 86, no. 4, pp. 79-82, 2010.

[18] R. Hiergeist, K. Wagner, and G. Ross, "Characterization of soft magnetic materials in AC magnetic fields by digital methods," Przeglad Elektrotechniczny, vol. 1, no. 7, pp. 45-49, 2017.

[19] J. Takács, "A phenomenological mathematical model of hysteresis," COMPEL-The International Journal for Computation and Mathematics in Electrical and Electronic Engineering, vol. 20, no. 4, pp. 1002-1015, 2001.

[20] F. A. Sampaio da Silva and M. F. de Campos, "A model for the hysteresis curves of soft magnetic materials," Materials Science Forum, vol. 727-728, pp. 130-134, 2012.

[21] D. C. Jiles and D. L. Atherton, "Theory of ferromagnetic hysteresis," Journal of Magnetism and Magnetic Materials, vol. 61, no. 1-2, pp. 48-60, 1986.

[22] D. Miljavec and B. Zidarič, "Introducing a domain flexing function in the Jiles-Atherton hysteresis model," Journal of Magnetism and Magnetic Materials, vol. 320, no. 5, pp. 763768, 2008.

[23] B. Ślusarek, K. Chwastek, J. Szczygłowski, and B. Jankowski, "Modeling hysteresis loops of SMC cores," Solid State Phenomena, vol. 220-221, pp. 652-660, 2015.

[24] A. Benabou, S. Clénet, and F. Piriou, "Comparison of Preisach and Jiles-Atherton models to take into account hysteresis phenomenon for finite element analysis," Journal of Magnetism and Magnetic Materials, vol. 261, no. 1-2, pp. 139-160, 2003.

[25] M. Belkadi, B. Ramdane, D. Trichet, and J. Fouladgar, "Non linear homogenization for calculation of electromagnetic 
properties of soft magnetic composite materials," IEEE Transactions on Magnetics, vol. 45, no. 10, pp. 4317-4320, 2009.

[26] L. A. Righi, N. Sadowski, R. Carlson, J. P. A. Bastos, and N. J. Batistela, "A new approach for iron losses calculation in voltage fed time stepping finite elements," IEEE Transactions on Magnetics, vol. 37, no. 5, pp. 3353-3356, 2001.

[27] K. Zakrzewski, "Berechnung der Wirk- und Blindleistung in einem ferromagnetischen Blech unter Berücksichtigung der komplexenmagnetischen Permeabilität," Wissenschaftliche Zeitschrift der TH Ilmenau, vol. 5, no. 16, pp. 101-105, 1970.

[28] E. Cardelli and E. Della Torre, "Modeling of hysteresis and dynamic losses in soft ferrites up to radiofrequency level," Physica B: Condensed Matter, vol. 306, no. 1-4, pp. 240-245, 2001.

[29] M. C. Rodriguez and C. Sanz, "Simple frequency domain model for hysteresis and eddy currents in cylindrical and parallelepipedal cores," IEEE Transactions on Magnetics, vol. 43, no. 5, pp. 1912-1919, 2007.

[30] M. A. Janaideh, S. Rakheja, and C.-Y. Su, "Experimental characterization and modeling of rate-dependent hysteresis of a piezoceramic actuator," Mechatronics, vol. 19, no. 5, pp. 656-670, 2009.

[31] G. Gu and L. Zhu, "Modeling of rate-dependent hysteresis in piezoelectric actuators using a family of ellipses," Sensors and Actuators A: Physical, vol. 165, no. 2, pp. 303-309, 2011.

[32] O. Gal, Matlab script “fit_ellipse.m”, https://www.mathworks. com/matlabcentral/fileexchange/3215-fit_ellipse. 


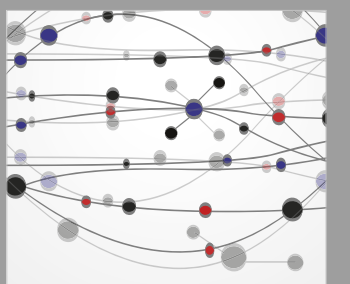

The Scientific World Journal
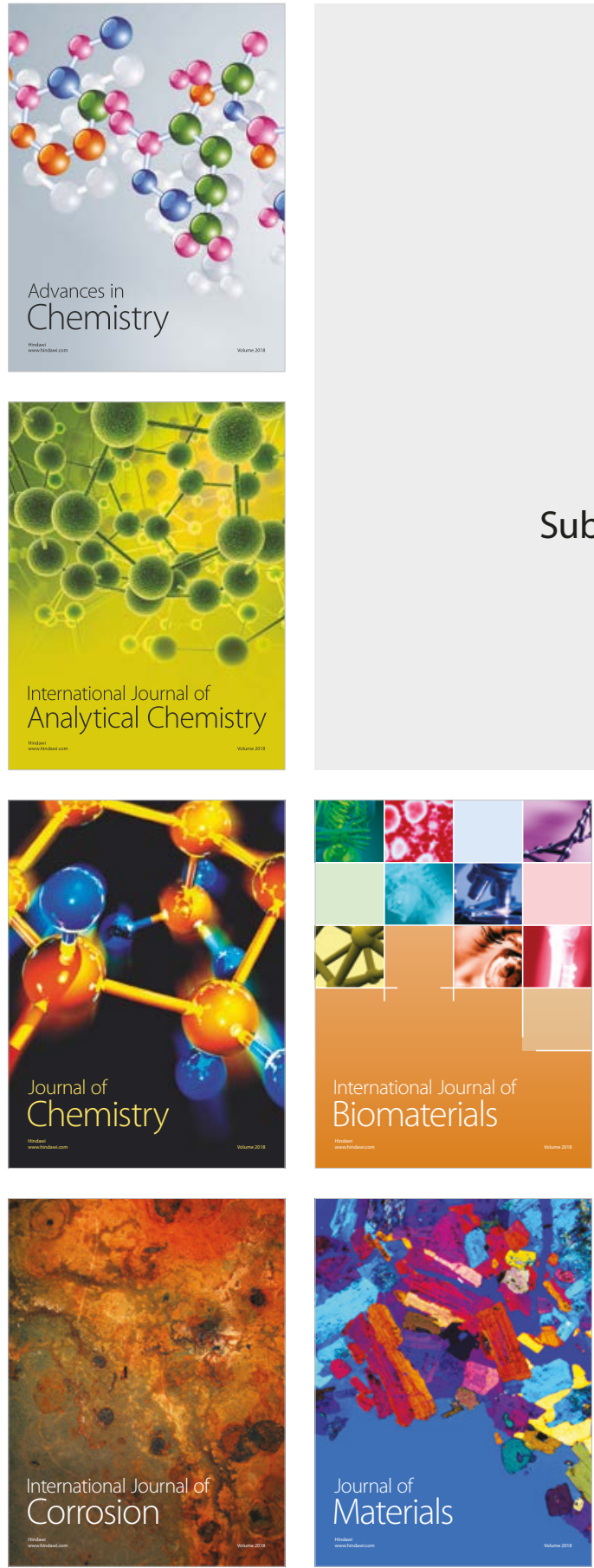

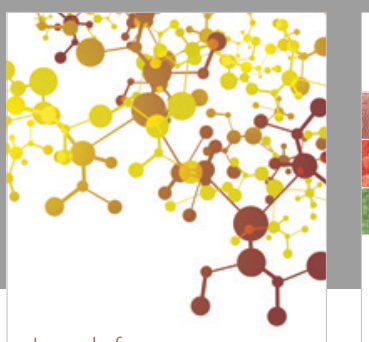

Journal of

Applied Chemistry
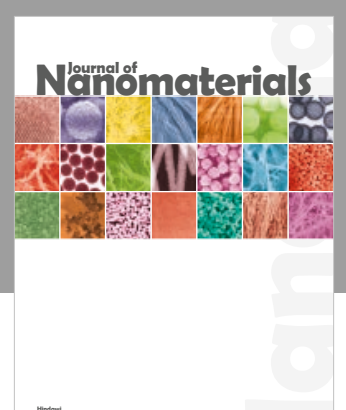

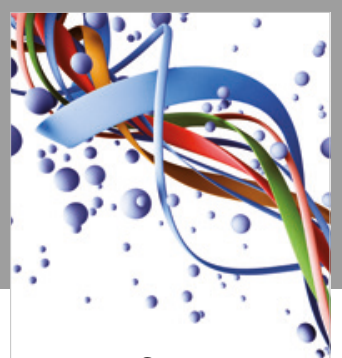

Scientifica

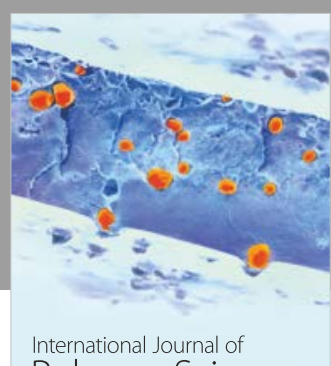

Polymer Science

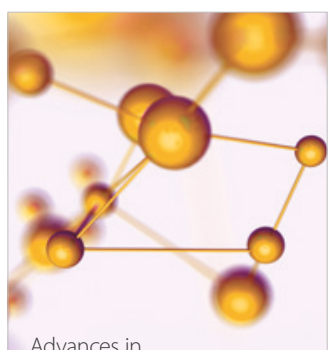

Physical Chemistry
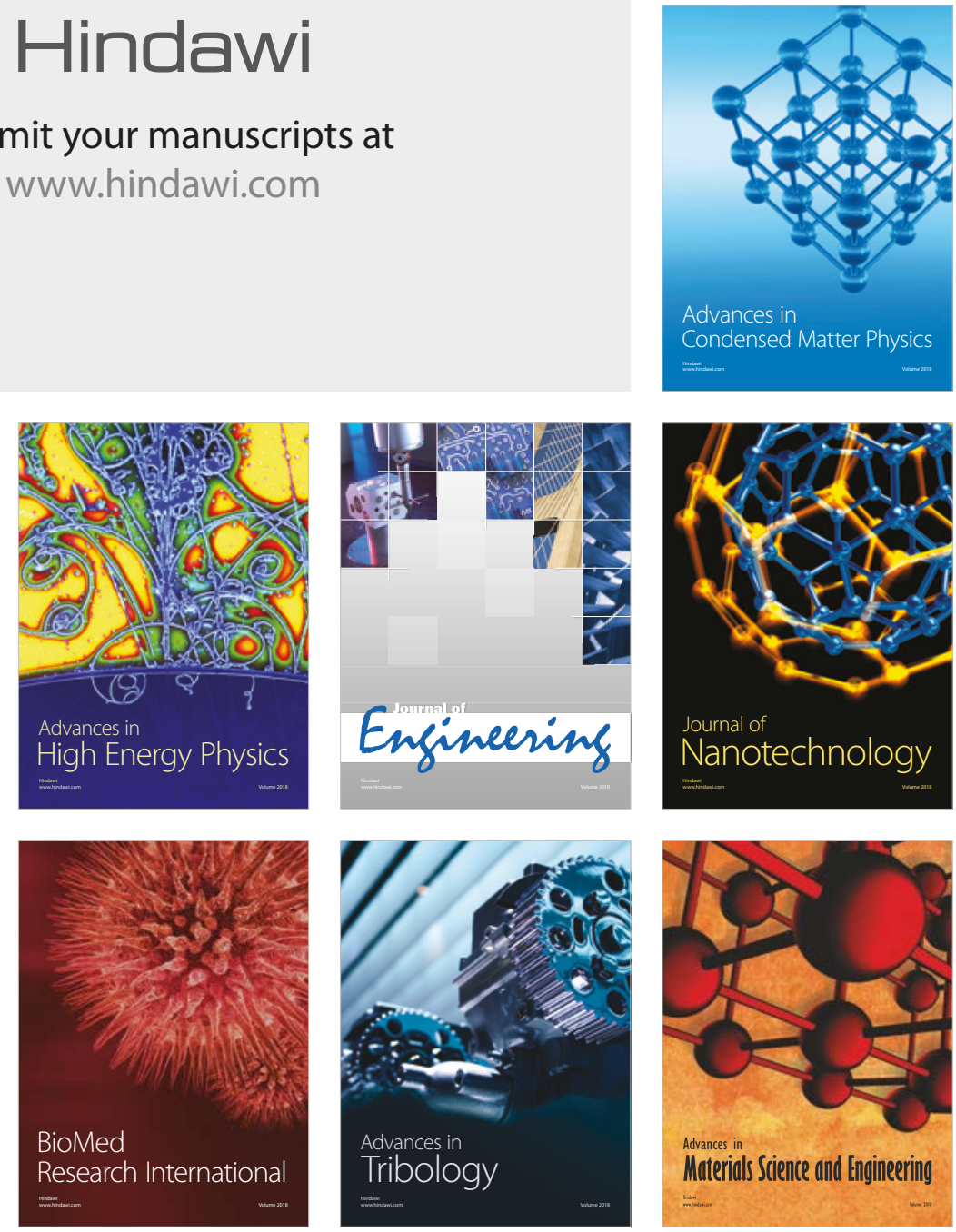